\title{
Serum aspartate transaminase changes following open-heart surgery with ischaemic arrest (with and without coronary artery perfusion)
}

\author{
W. A. LITTLER ${ }^{1}$, J.B. MEA DE, C. C. EVA N , a nd \\ G. D A VIES
}

The Regional Cardio-Thoracic Centre, Broadgreen Hospital, Liverpool

Patients with aortic disease irrespective of whether they had coronary perfusion or not showed a significant difference in the level of postoperative SGOT levels compared with other groups. Aortics with coronary perfusion did not show a correlation between SGOT levels and total perfusion time while the other groups did. The levels were not of prognostic significance.

Abundant literature is available on the alterations in the level of serum aspartate transaminase after various surgical procedures, particularly following cardiac surgery, and therefore any further work on this subject might seem superfluous (Welbourn, Melrose, and Moss, 1966). However, several points are worth noting: the overwhelming majority of patients in the earlier studies had congenital heart disease, the results were sometimes conflicting, and there was a divergence of opinion concerning the cause of the postoperative increase in enzyme levels. More relevant to the present study is the fact that most of the previous work was published before Cooley and his colleagues (1964) introduced cross clamping of the aorta with ischaemic cardiac arrest to facilitate the insertion of prosthetic valves.

Bloodwell, Gill, Pereyo, Hallman, De Bakey and Cooley (1966) found no significant difference in either the postoperative course or enzyme levels between patients having aortic occlusion plus selective coronary perfusion and those having aortic occlusion alone.

Recently, Reid (1970) studied the changes in serum aspartate aminotransferase (SGOT) and serum alanine aminotransferase (SGPT) levels in 25 patients who underwent open-heart surgery with aortic occlusion and no coronary perfusion, and showed that while these enzyme levels were initially markedly raised, they had returned to normal by the 21 st postoperative day.

In the present study we were concerned principally in comparing the postoperative levels of SGOT in patients with different heart lesions and assessing what factors might be contributing to these levels. We have used only SGOT levels as it is a readily available routine laboratory estimation.

T A B LE I

BREAKDOWN OF 90 PATIENTS INTO FIVE GROUPS ACCORDING TO THEIR MAIN LESION

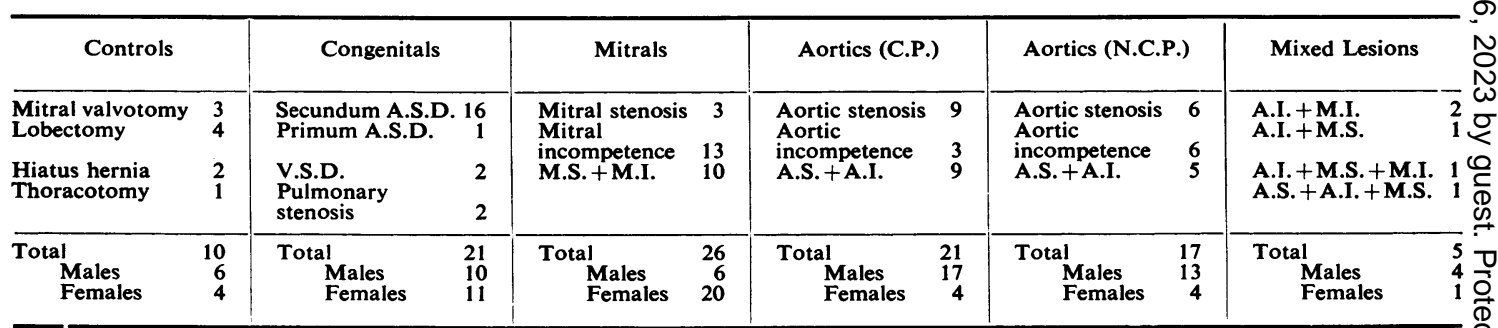

$\overline{\text { C.P. }}=$ coronary perfusion; N.C.P. $=$ no coronary perfusion; A.S.D. $=$ atrial septal defect; V.S.D. $=$ ventricular septal defect; M.S. $=$ mitral $\stackrel{\Omega}{ }$ stenosis; M.I. = mitral incompetence; A.S. = aortic stenosis; A.I. =: aortic incompetence.

1Present address: The Radcliffe Infirmary, Oxford 
PATIENTS AND METHODS

The series was compiled from patients undergoing open-heart surgery during a 10 -month period in this centre. Those who did not survive the first 48 hours after operation or who had evidence of severe liver damage, pre or postoperatively, were excluded, leaving a total of 90 patients in the study. None had suffered a previous myocardial infarct. These patients were then divided into five groups on the basis of their primary cardiac lesion (Table I). Ten patients undergoing thoracotomy for a variety of conditions were used as control subjects. The cardiac operations were performed under normothermic conditions and cardiopulmonary bypass was carried out using a disposable plastic bubble oxygenator (Rygg) with a non-blood prime (Hartmann's solution, 2 litres; heparin, 600,000 units; and $5 \%$ sodium bicarbonate solution, $60 \mathrm{ml}$ ). Selective coronary artery perfusion was effected through a short hard-tipped balloon catheter (Polystan) using a separate roller pump (De Bakey) whose pressure was not allowed to exceed $100 \mathrm{mmHg}$.

On return to the intensive care ward many of the patients who had undergone mitral valve replacement required intermittent positive pressure ventilation during the first 24 hours but only a minority of the other patients were ventilated.

Intravenous $5 \%$ dextrose solution, potassium chloride, isoprenaline, frusemide, and opiates, together with intramuscular or oral digoxin, were the most commonly used drugs in the first 72 hours postoperatively.

All blood samples were taken by venepuncture or through a central venous line in the superior vena cava. Estimations of the level of SGOT were made on these blood samples within six hours by the method of Babson, Shapiro, Williams, and Phillips (1962) using a commercially available kit (Warner 'Transac') expressing the results in international units per litre serum.

Blood samples were drawn on the day before operation and at 9 a.m. on each of the first three postoperative days. The mean value of these three levels was used to represent the postoperative figure. Badly haemolysed specimens were rejected.

\section{RESULTS}

The mean values, with appropriate standard deviation and range, for age, time of total perfusion, ischaemic arrest, and coronary artery perfusion, together with the pre and postoperative levels of SGOT are shown in Table II.

There was no significant difference between the mean preoperative SGOT in the control group and the five groups of patients undergoing open-heart surgery. However, they all differed significantly from the control in the postoperative period $(\mathrm{P}<0.05)$. When the five groups were compared with one another it was found that patients undergoing aortic valve replacement had a significantly higher postoperative SGOT level than the other three groups irrespective of whether the coronaries were perfused or not (perfused group, $t=2 \cdot 55$; $\mathbf{P}<0.01$; non-perfused group, $t=2 \cdot 29, \mathbf{P}<0.02$ ). There was, however, no significant difference between these two groups.

\section{LENGTH OF TOTAL PERFUSION}

A significant correlation was found between the length of bypass and the postoperative SGOT level in the following groups:

(a) congenitals $(\mathrm{r}=0.7129 ; \mathrm{P}<0.001)$

(b) mitrals ( $\mathrm{r}=0.6745 ; \mathrm{P}<0.001)$

(c) non-coronary perfused $(\mathrm{r}=0.6563 ; \mathrm{P}<0.01)$ aortics.

\section{LENGTH OF ISCHAEMIC ARREST}

A significant correlation was found between this and the postoperative SGOT level in

(a) congenitals $(\mathrm{r}=0.6027 ; \mathrm{P}<0.001)$

(b) non-coronary perfused aortics ( $r=0.6716$; $\mathrm{P}<0.001)$.

T A B L E I I

MEAN VALUES, STANDARD DEVIATION, AND RANGE

\begin{tabular}{|c|c|c|c|c|c|c|}
\hline & Controls & Congenitals & Mitrals & Aortics (C.P.) & Aortics (N.C.P.) & Mixed Lesions \\
\hline $\begin{array}{l}\text { Age } \\
\text { Perfusion time (min) } \\
\text { Cross clamp time (min) } \\
\text { Coronary perfusion time } \\
\text { (min) } \\
\text { Preop. SGOT } \\
\text { Postop. SGOT }\end{array}$ & $\begin{array}{c}38 \cdot 4 \pm 8 \\
(30-46) \\
60 \pm 27 \\
(39-100)\end{array}$ & $\begin{array}{c}35 \pm 11 \\
(19-53) \\
44 \cdot 4 \pm 19 \cdot 3 \\
(19 \pm 96) \\
22 \cdot 0 \pm 13 \cdot 3 \\
(5-54) \\
\\
38 \pm 8 \\
(21-50) \\
99 \pm 53 \\
(61-278)\end{array}$ & $\begin{array}{c}46 \pm 7 \\
(34-60) \\
90 \cdot 4 \pm 35 \cdot 0 \\
(45-205) \\
46 \cdot 7 \pm 11 \cdot 8 \\
(26-68) \\
\\
38 \pm 8 \\
(21-55) \\
103 \pm 44 \\
(58-298)\end{array}$ & $\begin{array}{c}48 \pm 8 \\
(23-60) \\
106 \cdot 2 \pm 40 \cdot 1 \\
(64-299) \\
34 \cdot 5 \pm 20 \cdot 6 \\
(19-85) \\
50 \cdot 4 \pm 15 \cdot 5 \\
(22-75) \\
34 \pm 7 \\
(14-46) \\
203 \pm 178 \\
(56-660)\end{array}$ & $\begin{array}{c}43 \pm 11 \\
(24-62) \\
90 \cdot 6 \pm 24 \cdot 9 \\
(60-145) \\
57 \cdot 9 \pm 12 \cdot 9 \\
(41-84) \\
\\
37 \pm 10 \\
(27-47) \\
191 \pm 141 \\
(53-419)\end{array}$ & $\begin{array}{c}41 \pm 8 \\
(29-46) \\
84 \cdot 6 \pm 46 \cdot 5 \\
(80-117) \\
19 \cdot 7 \pm 10 \cdot 6 \\
(6-53) \\
54 \cdot 6 \pm 15 \cdot 0 \\
(45-72) \\
33 \pm 3 \\
(29-45) \\
103 \pm 22 \\
(80-141)\end{array}$ \\
\hline
\end{tabular}




\section{LENGTH OF CORONARY PERFUSION}

There was no significant correlation with the postoperative SGOT levels.

\section{HOSPITAL DEATHS}

Fourteen patients died in hospital (Table III). No connexion was established between the SGOT level and those patients who died. One patient who died from a myocardial infarction after aortic valve replacement had an SGOT level postoperatively of 295 (range 53-419 for that group).

T A B L E I I I

CAUSE OF DEATH AND INDIVIDUAL GROUPS: 14 (15\%) HOSPITAL DEATHS

\begin{tabular}{|c|c|c|c|c|c|}
\hline \multicolumn{2}{|l|}{ Lesion } & \multicolumn{2}{|c|}{$\begin{array}{l}\text { Deaths } \\
\text { No. } \%\end{array}$} & \multicolumn{2}{|l|}{ Cause } \\
\hline Congenital . & .. & 1 & $4 \cdot 7$ & Air embolus & 1 \\
\hline Mitral & $\cdots$ & 5 & $19 \cdot 2$ & $\begin{array}{l}\text { Cerebral damage } \\
\text { Bronchopneumonia } \\
\text { Cardiac failure }\end{array}$ & $\begin{array}{l}2 \\
2 \\
1\end{array}$ \\
\hline Aortic & $\cdots$ & 7 & $19 \cdot 4$ & & \\
\hline Perfused & $\cdots$ & 4 & $11 \cdot 0$ & $\begin{array}{l}\text { Bacterial endocarditis } \\
\text { Mediastinitis } \\
\text { Bronchopneumonia } \\
\text { Cerebral damage }\end{array}$ & $\begin{array}{l}1 \\
1 \\
1 \\
1\end{array}$ \\
\hline Non-perfuse & sed & 3 & $8 \cdot 4$ & $\begin{array}{l}\text { Myocardial infarct } \\
\text { Cerebral damage }\end{array}$ & $\begin{array}{l}1 \\
2\end{array}$ \\
\hline Mixed & . & 1 & $20 \cdot 0$ & Bronchopneumonia & 1 \\
\hline
\end{tabular}

\section{DISCUSSION}

The level of SGOT is hardly a comprehensive assessment of myocardial damage; it is, however, a commonly used and relatively easily performed index in clinical practice.

Patients with aortic valve disease stand out clearly as having significantly higher postoperative SGOT levels in this series. Previous studies have not strictly compared large groups of patients with acquired heart disease. In Reid's (1970) group of 25 patients, 17 had mitral disease, whereas only four had aortic disease; it is not surprising, therefore, that no significant difference emerged.

It is not known why those who have had aortic valve replacement should have such high levels but $\stackrel{\bar{\equiv}}{\stackrel{\bar{S}}{+}}$ it is likely that it is related to the large left ventricular muscle mass. Indeed, preoperatively, the $\overline{\bar{O}}$ blood supply may be only just adequate, and during $\frac{D}{\vec{D}}$ surgery not sufficient, to prevent ischaemia. That $\mathbb{D}$ the two groups of patients with aortic valve disease \& do not differ significantly is perhaps surprising, $\vec{O}$ although in keeping with the findings of Bloodwell et al. (1966). Whatever benefit coronary perfusion $\vec{\omega}$ has, it is not reflected in the SGOT levels.

However, only those aortic patients who had $\vec{x}$ coronary perfusion did not show a correlation between total perfusion time and the SGOT levels, $\stackrel{\sim}{-}$ and perhaps this is indicative of some protective mechanisms; in other words, their SGOT levels may $N$ have been even higher without coronary perfusion. 의 Also those with coronary perfusion did not show a correlation with ischaemic arrest time whereas the non-perfused aortics did. The patients with mitral disease are probably more accustomed to relatively anoxic conditions than are the patients with acyanotic congenital lesions; and this may explain the lack of correlation in the mitral group ? between ischaemic time and SGOT.

We should like to thank Mr D. I. Hamilton and Mr. L. J. Temple for permission to study their patients and Miss P. Ashworth for supervising the collection of $\frac{\mathbb{D}}{2}$ blood samples.

\section{REFERENCES}

Babson, A. L., Shapiro, P. O., Williams, P. A. R., and Phillips, G. E. (1962). The use of a diazonium salt for? the determination of glutamic-oxalacetic transaminase in serum. Clin. chim. Acta, 7, 199.

Bloodwell R. D., Gill, S. S., Pereyo, J. A., Hallman, G. L., 궁 De Bakey, M. E., and Cooley, D. A. (1966). Cardiac valve replacement without coronary perfusion. Circulation, 33-34, Suppl. III, 58.

Cooley, D. A., Nelson, T. G., Beall, A. C., and De Bakey, M. E. (1964). Prosthetic replacement of cardiac valves. Dis. Chest, 46, 339.

Reid, J. M. (1970). Serum transaminase levels following cross-clamping of the aorta in open heart surgery without coronary artery perfusion. Scot. med.J., 15, 176.

Welbourn, N., Melrose, D. G., and Moss, D. W. (1966). N Changes in serum enzyme levels accompanying cardiac S surgery with extracorporeal circulation. J. clin. Path., N 19, 220. 